\title{
Pediatric neurosurgery training during residency in the United States: a program director survey
}

\author{
Natalie Limoges, DO, ${ }^{1}$ Erin D’Agostino, MD, ${ }^{1}$ Aaron Gelinne, MD, ${ }^{2}$ Cormac O. Maher, MD, ${ }^{3}$ \\ R. Michael Scott, MD, ${ }^{4}$ Gerald Grant, MD, ${ }^{5}$ Mark D. Krieger, MD, ${ }^{6}$ David D. Limbrick Jr., MD, PhD, ${ }^{7}$ \\ Michael White, BS, ${ }^{8}$ and Susan Durham, MD ${ }^{1}$ \\ ${ }^{1}$ Division of Neurological Surgery, University of Vermont Medical Center, Burlington, Vermont; ${ }^{2}$ Department of Neurological \\ Surgery, University of North Carolina, Chapel Hill, North Carolina; ${ }^{3}$ Department of Neurological Surgery, University of \\ Michigan, Ann Arbor, Michigan; “Department of Neurological Surgery, Boston Children's Hospital, Harvard University, Boston, \\ Massachusetts; ${ }^{5}$ Department of Neurological Surgery, Stanford University, Palo Alto, California; ${ }^{6}$ Department of Neurological \\ Surgery, Children's Hospital Los Angeles, California; 'Department of Neurological Surgery, Washington University, St. Louis, \\ Missouri; and ${ }^{8}$ Department of Neurological Surgery, University of Pittsburgh Medical Center, Pittsburgh, Pennsylvania
}

\begin{abstract}
OBJECTIVE Pediatric neurosurgery is a core component of neurosurgical residency training. Pediatric case minimums are established by the Neurosurgery Residency Review Committee of the Accreditation Council for Graduate Medical Education (ACGME). Case minimums, by themselves, allow for great variability in training between programs. There are no prior data on how the residency programs meet these requirements. The authors' objective was to gather information on pediatric neurosurgical education among the ACGME-accredited neurosurgery training programs in order to shape further pediatric neurosurgical educational efforts.
\end{abstract}

METHODS A 25-question survey about pediatric neurosurgical education was created by the Education Committee of the Section on Pediatric Neurological Surgery of the American Association of Neurological Surgeons/Congress of Neurological Surgeons and distributed to program directors of all 111 ACGME-accredited neurosurgery training programs.

RESULTS The response rate was $77 \%$ (86/111). In 55\% of programs the residents are rotated to a responder-designated "freestanding" children's hospital, and $39 \%$ of programs rotate residents to a children's hospital within a larger adult hospital or a general hospital. There are 4 or fewer pediatric neurosurgical faculty in $91 \%$ of programs. In $12 \%$ of programs less than 100 cases are performed per year, and in $45 \%$ more than 500 are performed. In $31 \%$ of responding neurosurgery residency programs there is also a pediatric neurosurgery fellowship program supported by the same sponsoring institution. Seventy-seven percent of programs have at least one specific pediatric neurosurgery rotation, with $71 \%$ of those rotations occurring during postgraduate year 3 and $50 \%$ occurring during postgraduate year 4 . The duration of pediatric rotation varies from no specific rotation to more than 1 year, with $48 \%$ of residents spending 4-6 months on a pediatric rotation and $12 \%$ spending $7-11$ months. Last, $17 \%$ of programs send their residents to external sites sponsoring other residency programs for their pediatric rotation.

CONCLUSIONS There is great variety between neurosurgery training programs with regard to resident education in pediatric neurosurgery. This study's data will serve as a baseline for future studies, and the authors hope the findings will guide further efforts in pediatric neurosurgical education in residency training programs.

https://thejns.org/doi/abs/10.3171/2020.1.PEDS19662

KEYWORDS pediatric neurosurgery; medical education; case volume; competency

$\mathrm{T}$ HE origins of organized pediatric neurosurgery in the US can be traced back to 1929, when Franc D. Ingraham started the first pediatric neurosurgical service at Boston Children's Hospital. ${ }^{1}$ The first formal events of organized pediatric neurosurgery occurred many years later. The first meeting of the pediatric section of the AANS was in 1971. Following this, the American Soci- ety of Pediatric Neurosurgeons (ASPN) started in 1978 as an informal meeting among 18 North American pediatric neurosurgeons-its mission dedicated to the advancement of all aspects of the subspecialty of pediatric neurological surgery. ${ }^{2}$ Over the ensuing 2 decades, pediatric neurosurgery established itself as a distinct subspecialty within neurosurgery, with pediatric-specific postgraduate

ABBREVIATIONS ACGME = Accreditation Council for Graduate Medical Education. 
training and board certification requirements. In 1991, the American Board of Pediatric Neurological Surgery was established to encourage the study, improve the practice, and elevate the standards of pediatric neurological surgery and to codify the optimal training and practice requirements for pediatric neurosurgeons. Shortly thereafter, in 1992, the Accreditation Council for Pediatric Neurosurgical Fellowships (ACPNF) was established to accredit pediatric neurosurgery fellowships and ensure adequate training of pediatric neurosurgeons.

Although these efforts have been effective in standardizing pediatric neurosurgical fellowships and board certification of pediatric neurosurgeons, pediatric neurosurgery training during residency is still quite variable. For residency accreditation, the paramount measure of pediatric neurosurgical education during residency has been case minimums, resulting in a system largely open to interpretation and significant individual variation. ${ }^{3}$ Over the past decade, tools such as Milestones have been developed in an effort to standardize the education and evaluation of neurosurgical residents during their training. Implementation of an appropriate educational curriculum, whether based on case numbers, rotation duration, or objective measures of competency, requires analysis of the current exposure across a field and evaluation of what extent of exposure results in adequate training. To date, there are no published reports describing exposure to pediatric neurosurgery during residency training. That being the case, the goal of the current study was to define pediatric neurosurgery exposure and education during neurosurgery residency across all Accreditation Council for Graduate Medical Education (ACGME) training programs. We hope this will address the current gap in the care of pediatric neurosurgery patients across the US, particularly in trauma, because adult neurosurgeons may not feel comfortable caring for pediatric patients.

\section{Methods}

A 25-question survey on pediatric neurosurgical education during residency was created by the Education Committee of the Pediatric Neurosurgery Section of the AANS/CNS and distributed to all 111 ACGME-accredited neurosurgery training programs. The survey was distributed through SurveyMonkey to program directors via email. The survey was designed to determine the structural nature of pediatric training at each individual neurosurgery program. Specific areas of interest included program demographics (e.g., name, geographic location, and hospital type); resident demographics (e.g., number of residents); and pediatric-specific education structure, rotations, and case volume. Table 1 outlines the topics covered by the survey.

The survey solicited a response from 86 neurosurgery programs (response rate 77.4\%). Statistical analyses were performed using IBM SPSS Statistics (version 24.0, released 2016, IBM Corp.). Descriptive statistics were calculated based on responses to each survey question.

\section{Results}

Descriptive statistics for the entire cohort of programs included in this study $(n=86)$ are shown in Table 2 . The number of fellowship-trained pediatric neurosurgeons on the faculty at each program ranged from 1 to 7 (median $3)$. Fifty-five percent of the programs have a responderdesignated "freestanding" children's hospital, and 39.5\% of programs have a pediatric neurosurgery service that resides within a general hospital. Respondents were asked about pediatric case volume (defined as age $<21$ years), which was categorized as "less than 100," "100-500," "500-1000," or "greater than 1000." The pediatric case volume was between 100 and 500 cases per year in $43.4 \%$ of programs. Only $10.5 \%$ of programs had more than 1000 pediatric cases per year and $11.8 \%$ of programs had less than 100 pediatric cases per year (Fig. 1). The majority of programs reported that they have a dedicated pediatric neurosurgery rotation. The length of pediatric rotation varied in both formality and duration, with formal rotations ranging in duration from 3 months or less (22.2\%) to 1 year or more (8.6\%) (Fig. 2). The majority of programs have their pediatric neurosurgery training during the third or fourth year of residency (Fig. 3). Only 15 of the programs (17.4\%) reported sending their residents to an outside institution for their pediatrics rotation.

Most programs $(76.5 \%)$ report having a formalized pediatric neurosurgery education curriculum. Of those programs that report having a formal curriculum, 25.3\% have a formalized handbook or manual (e.g., lectures and readings), and $83.5 \%$ of the programs reported having formalized goals and expectations during their pediatric neurosurgery rotation. Of these programs, $55.1 \%$ had written handbooks and outlines that are disseminated to the residents. To evaluate resident performance on pediatric rotations, almost all programs used the (mandatory) general neurosurgical milestones (98.7\%), some used written evaluations (84.2\%), and some used faculty consensus (75.0\%). Only $3.9 \%$ of the programs used pediatric-specific written examinations to evaluate pediatric neurosurgery performance during residency training (Fig. 4). The programs that responded "other" regarding their form of resident evaluation reported using oral examinations or mock board examinations (4 programs), resident discussions ( 3 programs), nursing assessments ( 2 programs), and operative/technical evaluations following each case (2 programs).

\section{Discussion}

Determining whether residents are being appropriately trained in subspecialties within a field is a challenge faced by all residency programs. Educational data in the neurosurgical field specifically are limited, but examination of the literature regarding all fields can provide relevant insight. Currently, adequacy of training is primarily defined by case numbers, duration of assigned rotations, and competency-based evaluations. In Europe and Canada, educational methodology has begun to shift toward a more competency-based approach, in which residents are evaluated and deemed appropriately trained based primarily on those evaluations rather than completion of requisite hours or case numbers. ${ }^{4}$ Beginning in 2017, the Royal College of Physicians and Surgeons of Canada (RCPSC) announced 
TABLE 1. Survey questions regarding pediatric neurosurgery training

\begin{tabular}{|c|c|}
\hline Question & Answer Choices \\
\hline 1. Program name & Free text \\
\hline 2. Geographic location & Free text \\
\hline 3. Hospital type & Freestanding/children's hospital within an adult hospital/other \\
\hline 4. NACHRI-designated children's hospital? & Yes/no \\
\hline 5. Number of pediatric neurosurgery faculty & Number \\
\hline 6. Number of pediatric neurosurgery faculty who are ABPNS eligible or certified & Number \\
\hline $\begin{array}{l}\text { 7. Approximate number of pediatric neurosurgery cases/year (peds } \leq 21 \text { years of } \\
\text { age) at your institution }\end{array}$ & $\begin{array}{l}\text { Less than } 100 / 100-200 / 200-300 / 300-400 / 400-500 / 500- \\
\quad 600 / 600-700 / 700-800 / 800-900 / 900-1000 / \text { greater than } 1000\end{array}$ \\
\hline 8. Do you have a pediatric neurosurgery fellowship? & Yes/no \\
\hline 9. Number of residents/year in neurosurgery residency program & Number \\
\hline 10. Do you have a specific pediatric neurosurgery rotation at your institution? & Yes/no \\
\hline $\begin{array}{l}\text { 11. Do you send your residents to another program for a pediatric neurosurgery } \\
\text { rotation? }\end{array}$ & Yes/no \\
\hline 12. Length of pediatric neurosurgery rotation & 3 months $/ 6$ months $/ 1$ year/other \\
\hline $\begin{array}{l}\text { 13. What PGY do residents typically do their pediatric neurosurgery rotation (check } \\
\text { all that apply)? }\end{array}$ & PGY-1/PGY-2/PGY-3/PGY-4/PGY-5/PGY-6/PGY-7 \\
\hline $\begin{array}{l}\text { 14. Do you have residents from other institutions doing a pediatric neurosurgery } \\
\text { rotation at your program? }\end{array}$ & Yes/no \\
\hline 15. Do you have NPs or PAs on the pediatric neurosurgery service? & Yes/no \\
\hline 16. If yes, number of NPs or PAs on pediatric service & Number \\
\hline $\begin{array}{l}\text { 17. Do you have a pediatric neurosurgery-specific educational curriculum for the } \\
\text { residents (readings, lectures, etc.)? }\end{array}$ & Yes/no \\
\hline 18. If yes, how is it shared with the residents? & Formal handbook or manual/informal instruction/other \\
\hline 19. Do you have pediatric-specific goals and expectations for the rotation? & Yes/no \\
\hline 20. If yes, how is it shared with the residents? & Formal handbook or manual/informal instruction/other \\
\hline $\begin{array}{l}\text { 21. How do you evaluate resident performance on the pediatric neurosurgery rota- } \\
\text { tion (check all that apply)? }\end{array}$ & $\begin{array}{l}\text { Milestones/written evaluations/faculty consensus/pediatric- } \\
\text { specific written exam) }\end{array}$ \\
\hline $\begin{array}{l}\text { 22. Do you use any of the pediatric neurosurgery-specific educational material } \\
\text { provided on the "Portal"? }\end{array}$ & Yes/no \\
\hline 23. Do residents participate in pediatric neurosurgery outpatient clinics? & Yes/no \\
\hline $\begin{array}{l}\text { 24. Do the residents take pediatric neurosurgery-specific call (i.e., responsible } \\
\text { only for the children's hospital)? }\end{array}$ & Yes/no \\
\hline $\begin{array}{l}\text { 25. Do any nonresidents (NPs, PAs, fellows) take primary call for pediatric neuro- } \\
\text { surgery? }\end{array}$ & Yes/no \\
\hline
\end{tabular}

ABPNS = American Board of Pediatric Neurological Surgery; NACHRI = National Association of Children's Hospitals and Related Institutions; NP = nurse practitioner; $\mathrm{PA}=$ physician's assistant; $\mathrm{PGY}=$ postgraduate year.

a Competence by Design (CBD) initiative in which all postgraduate specialty programs in Canada were mandated to adopt a competency-based framework by $2022 .{ }^{5}$ The Division of Orthopaedic Surgery at the University of Toronto recently published results after 8 years of implementing such a curriculum, reporting a 1-year reduction in training duration for more than half of their residents. ${ }^{6}$

Such curricula are, however, limited both by expense and by lack of reliable evaluation tools or standardized curriculum. ${ }^{7}$ The ACGME requirements for training rely primarily on mandates regarding procedural minimums and to some extent on evaluation of the amount of time residents spend on different rotations during residency. We assumed that the 15 programs (17.4\%) that send their residents to another program for their pediatric neurosur- gery rotation are unable to meet the case minimums set by the Residency Review Committee. A recent analysis of US neurosurgical resident case logs demonstrated that the 877 residents who graduated between 2013 and 2017 on average logged more than three times the ACGMErequired volume of pediatric cases, with a trend toward more cases being logged as "lead resident surgeon" over time, suggesting that residents more than meet required standards and do so with increasing competency. Of note, the study also demonstrated a significant decrease in the number of cases logged during this interval. ${ }^{8}$

Case volumes alone may not provide enough information, given the significant variability in case volume measurements that have been reported across multiple fields, especially in increasingly subspecialized fields. In a sur- 
TABLE 2. Summary statistics for all neurosurgery programs that responded to survey

\begin{tabular}{|c|c|c|}
\hline Topic & No. & $\begin{array}{c}\% \text { of Total Respondents } \\
\text { to Question }\end{array}$ \\
\hline All participating programs & 86 & 100.0 \\
\hline Type of children's hospital & 86 & \\
\hline Inclusive & 34 & 39.5 \\
\hline Freestanding & 47 & 54.7 \\
\hline Other & 5 & 5.8 \\
\hline $\begin{array}{l}\text { NACHRI-designated children's } \\
\text { hospital? }\end{array}$ & 85 & \\
\hline Yes & 67 & 78.8 \\
\hline No & 18 & 21.2 \\
\hline No. of pediatric neurosurgery faculty & 86 & \\
\hline 1 & 19 & 22.1 \\
\hline 2 & 22 & 25.6 \\
\hline 3 & 22 & 25.6 \\
\hline 4 & 15 & 17.4 \\
\hline 5 & 5 & 5.8 \\
\hline 6 & 1 & 1.2 \\
\hline 7 & 2 & 2.3 \\
\hline $\begin{array}{l}\text { No. of pediatric neurosurgery faculty } \\
\text { who are ABPNS eligible or certified }\end{array}$ & 82 & \\
\hline 1 & 25 & 30.5 \\
\hline 2 & 22 & 26.8 \\
\hline 3 & 15 & 18.3 \\
\hline 4 & 12 & 14.6 \\
\hline 5 & 6 & 7.3 \\
\hline 6 & 2 & 2.4 \\
\hline $\begin{array}{l}\text { Approximate no. of pediatric neuro- } \\
\text { surgery cases/yr (pediatric } \leq 21 \text { yrs } \\
\text { of age) at your institution }\end{array}$ & 76 & \\
\hline$<100$ & 9 & 11.8 \\
\hline $100-500$ & 33 & 43.4 \\
\hline $500-1000$ & 26 & 34.2 \\
\hline$>1000$ & 8 & 10.5 \\
\hline $\begin{array}{l}\text { Do you have a pediatric neurosur- } \\
\text { gery fellowship? }\end{array}$ & 86 & \\
\hline Yes & 27 & 31.4 \\
\hline No & 59 & 68.6 \\
\hline $\begin{array}{l}\text { No. of residents/yr in neurosurgery } \\
\text { residency program? }\end{array}$ & 86 & \\
\hline 1 & 22 & 25.6 \\
\hline 1 or 2 : alternating yrs & 16 & 18.6 \\
\hline 2 & 18 & 20.9 \\
\hline 2 or 3 : alternating yrs & 10 & 11.6 \\
\hline 3 & 16 & 18.6 \\
\hline Other & 4 & 4.7 \\
\hline $\begin{array}{l}\text { Do you have a specific pediatric neu- } \\
\text { rosurgery rotation at your institution? }\end{array}$ & 86 & \\
\hline Yes & 66 & 76.7 \\
\hline No & 20 & 23.3 \\
\hline
\end{tabular}

» CONTINUED FROM PREVIOUS COLUMN

TABLE 2. Summary statistics for all neurosurgery programs that responded to survey

\begin{tabular}{ccc}
\hline Topic & No. & of Total Respondents \\
to Question
\end{tabular}

Do you send your residents to another program for a pediatric neurosurgery rotation?

\begin{tabular}{lcc}
\hline Yes & 15 & 17.4 \\
\hline No & 71 & 82.6 \\
\hline $\begin{array}{l}\text { Length of pediatric neurosurgery } \\
\text { rotation }\end{array}$ & 81 & \\
\hline$\leq 3$ mos & 18 & 22.2 \\
\hline $4-6$ mos & 39 & 48.2 \\
\hline $7-11$ mos & 10 & 12.4 \\
\hline 1 yr & 7 & 8.6 \\
\hline $\begin{array}{l}\text { Integrated throughout } \\
\begin{array}{l}\text { In what PGY do residents typically } \\
\text { do their pediatric neurosurgery rota- } \\
\text { tion (check all that apply)? }\end{array}\end{array}$ & 76 & 8.6 \\
\hline
\end{tabular}
tion (check all that apply)?

\begin{tabular}{lll}
\hline PGY-1 & 11 & 12.8 \\
\hline PGY-2 & 26 & 30.2 \\
\hline PGY-3 & 61 & 70.9 \\
\hline PGY-4 & 43 & 50.0 \\
\hline PGY-5 & 20 & 23.3 \\
\hline PGY-6 & 23 & 26.7 \\
\hline PGY-7 & 15 & 17.4 \\
\hline
\end{tabular}

Do you have residents from other institutions doing a pediatric neurosurgery rotation at your program?

\begin{tabular}{ccc} 
Yes & 15 & 17.6 \\
\hline No & 70 & 82.4 \\
\hline $\begin{array}{l}\text { Do you have NPs or PAs on the } \\
\text { pediatric neurosurgery service? }\end{array}$ & 86 & \\
\hline Yes & 68 & 79.1 \\
\hline No & 18 & 20.9 \\
\hline
\end{tabular}

If there are NPs or PAs on service, 65 no. of NPs or PAs on pediatric service*

\begin{tabular}{lrc}
\hline 1 & 20 & 30.8 \\
\hline 1.2 & 1 & 1.5 \\
\hline 1.25 & 1 & 1.5 \\
\hline 1.5 & 1 & 1.5 \\
\hline 2 & 12 & 18.5 \\
\hline 3 & 9 & 13.9 \\
\hline 4 & 9 & 13.9 \\
\hline 5 & 6 & 9.2 \\
\hline 6 & 3 & 4.6 \\
\hline 7 & 1 & 1.5 \\
\hline 10 & 2 & 3.1 \\
\hline & & CONTINUED ON PAGE 10
\end{tabular}


» CONTINUED FROM PAGE 9

TABLE 2. Summary statistics for all neurosurgery programs that responded to survey

\begin{tabular}{|c|c|c|}
\hline Topic & No. & $\begin{array}{c}\% \text { of Total Respondents } \\
\text { to Question }\end{array}$ \\
\hline $\begin{array}{l}\text { Do you have a pediatric neurosur- } \\
\text { gery-specific educational curriculum } \\
\text { for the residents (readings, lectures, } \\
\text { etc.)? }\end{array}$ & 85 & \\
\hline Yes & 65 & 76.5 \\
\hline No & 20 & 23.5 \\
\hline $\begin{array}{l}\text { If yes, how is it shared with resi- } \\
\text { dents? }\end{array}$ & 75 & \\
\hline Formal handbook or manual & 19 & 25.3 \\
\hline Informal instruction & 38 & 50.7 \\
\hline Other & 18 & 24.0 \\
\hline $\begin{array}{l}\text { Do you have pediatric-specific goals } \\
\text { and expectations for the rotation? }\end{array}$ & 85 & \\
\hline Yes & 71 & 83.5 \\
\hline No & 14 & 16.5 \\
\hline $\begin{array}{l}\text { If yes, how is it shared with the } \\
\text { residents? }\end{array}$ & 78 & \\
\hline Printed or electronic material & 43 & 55.1 \\
\hline Informal instruction & 28 & 35.9 \\
\hline Other & 7 & 9.0 \\
\hline $\begin{array}{l}\text { How do you evaluate resident perfor- } \\
\text { mance on the pediatric neurosurgery } \\
\text { rotation (check all that apply)? }\end{array}$ & 76 & \\
\hline Milestones & 75 & 98.7 \\
\hline Written evaluations & 64 & 84.2 \\
\hline Faculty consensus & 57 & 75.0 \\
\hline $\begin{array}{l}\text { Pediatric-specific written } \\
\text { examination }\end{array}$ & 3 & 3.9 \\
\hline Other & 9 & 11.8 \\
\hline $\begin{array}{l}\text { Do you use any of the neurosurgery- } \\
\text { specific educational material } \\
\text { provided on the "Portal"? }\end{array}$ & 85 & \\
\hline Yes & 13 & 15.3 \\
\hline No & 60 & 70.6 \\
\hline Don't know what the "Portal" is & 12 & 14.1 \\
\hline $\begin{array}{l}\text { Do residents participate in pediatric } \\
\text { neurosurgery outpatient clinics? }\end{array}$ & 85 & \\
\hline Yes (<4 hrs/wk) & 44 & 51.8 \\
\hline Yes (4-8 hrs/wk) & 23 & 27.1 \\
\hline Yes (>8 hrs/wk) & 6 & 7.1 \\
\hline No & 10 & 11.8 \\
\hline Other & 2 & 2.4 \\
\hline $\begin{array}{l}\text { Do the residents take pediatric } \\
\text { neurosurgery-specific call (i.e., } \\
\text { responsible only for the children's } \\
\text { hospital)? }\end{array}$ & 85 & \\
\hline Yes & 37 & 43.5 \\
\hline No & 48 & 56.5 \\
\hline
\end{tabular}

》 CONTINUED FROM PREVIOUS COLUMN

TABLE 2. Summary statistics for all neurosurgery programs that responded to survey

\begin{tabular}{lcc}
\hline \multicolumn{1}{c}{ Topic } & No. & $\begin{array}{c}\% \text { of Total Respondents } \\
\text { to Question }\end{array}$ \\
\hline $\begin{array}{l}\text { Do any nonresidents (NPs, PAs, fel- } \\
\text { lows) take primary call for pediatric } \\
\text { neurosurgery? }\end{array}$ & 85 & \\
\hline Yes & & \\
\hline No & 19 & 22.4 \\
\hline
\end{tabular}

Not all participants answered every question. The number of respondents is specified next to the corresponding question.

* Fractional values for this entry refer to having one full-time and one part-time PA or NP.

vey of 115 ACGME-accredited orthopedic surgery program schedules, significant variability was noted-with a range of nonexistent to more than 12 months of time dedicated to subfields like sports medicine and arthroplasty. ${ }^{4}$ Variability has been specifically reported in pediatric aspects of residency training. Hinds et al. reported recently on significant variability in exposure to pediatric orthopedic surgery: graduating residents between 2007 and 2013 demonstrated case volumes in the 10th-90th percentile, ranging from 169 to 524 procedures. ${ }^{9}$ Exposure to pediatric surgery is also quite varied among programs. A 2016 survey of pediatric surgery residents in France highlighted the finding that residents did not feel confident in complex pediatric surgical situations and strongly desired supplementary training. ${ }^{10}$ In 2018, as a result of these findings and in an attempt to provide standardized, supplementary training, the National Pediatric Surgery Simulation Program was developed. The program was designed as a 2-day, multicenter, mandatory national program for all pediatric surgery residents and was well received. ${ }^{11}$ The desire for further training corresponds to the increasing number of general surgery residents in the US who seek subspecialty training in pediatrics following residency. ${ }^{12}$

Ensuring adequate training has been acknowledged as particularly challenging for subspecialty fields like pediatrics, which is set apart by the variability and complexity of cases and the rarity of many of the conditions addressed, as well as a unique overlay of required skills associated with the child-parent-physician relationship. Corresponding with this sentiment, the 2017-2018 American Board of Surgery states that "comprehensive knowledge and management of conditions in pediatric surgery generally requires additional training." 13 A decline in pediatric subspecialization secondary to inadequate exposure could have an impact on the workforce as a whole..$^{14}$ Therefore, it is critical that residents within neurosurgery are adequately exposed and trained in this subspecialty.

The current study demonstrates that although residents on average log more than three times the required number of pediatric cases, ${ }^{8}$ pediatric neurosurgery exposure during residency training remains extremely variable. Much of this is probably due to the institution-dependent exposure to pediatric neurosurgery and the lack of a stan- 


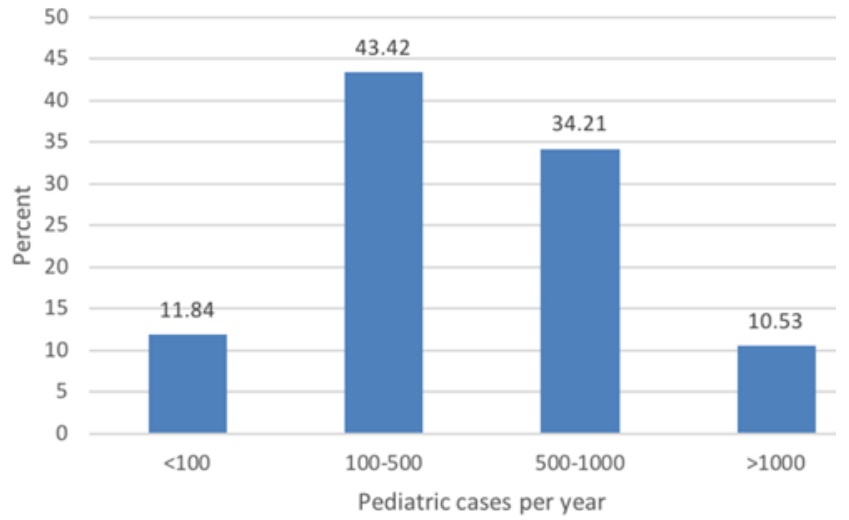

FIG. 1. Percent of respondents reporting $<100,100-500,500-1000$, and $>1000$ pediatric cases per year. Figure is available in color online only.

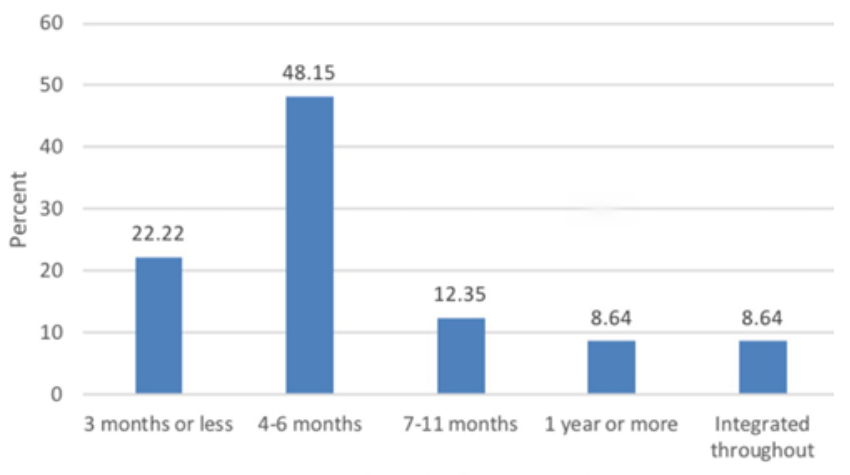

Duration of pediatrics rotation

FIG. 2. Percent of respondents reporting 3 months or less, 4-6 months, 7-11 months, 1 year or more, or integrated duration of pediatrics rotation. Figure is available in color online only.

dardized curriculum. This is evident in our survey by the variability in case volume, year of rotation, length of rotation, presence of a formal curriculum, and presence of a freestanding children's hospital. Variability of exposure is similarly reported by Samuel et al. in their evaluation of exposure to stereotactic radiosurgery during neurosurgical residency. ${ }^{15}$ Case minimums alone should not be the sole measure of adequate training within neurosurgery. Creation of a more standardized curriculum that additionally focuses on discrete rotations and competency-based evaluation may result in improved training in pediatric neurosurgery as well as other subspecialties.

Our study was limited by the subjective nature of a survey and an incomplete cohort (77.4\% response rate). Additionally, the data are self-reported and nonvalidated, but we believe they are adequate to identify the significant variability in training that exists. This highlights the inconsistency in training experience and lack of competency-based measures. We hope these data stimulate centers to find solutions to close the gap in competence for pediatric neurosurgery. By achieving more consistent and competency-based training in hydrocephalus and trauma

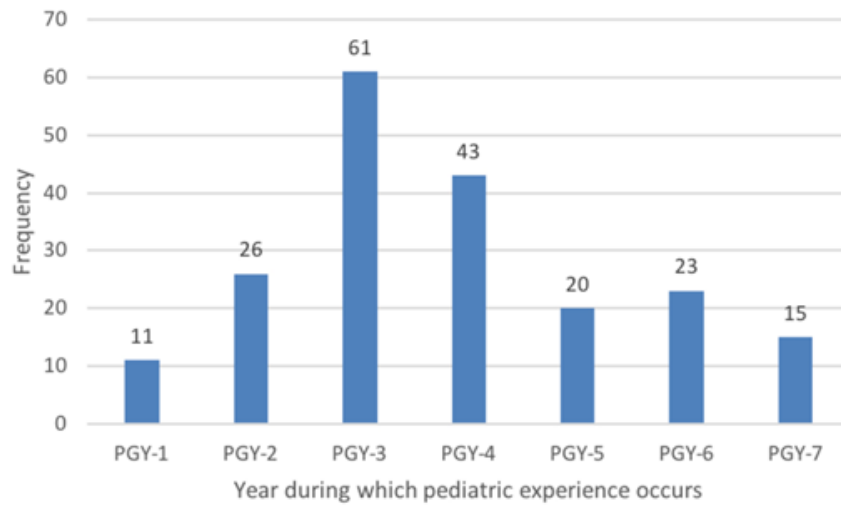

FIG. 3. Frequency of exposure to pediatrics based on postgraduate year (PGY). Figure is available in color online only.

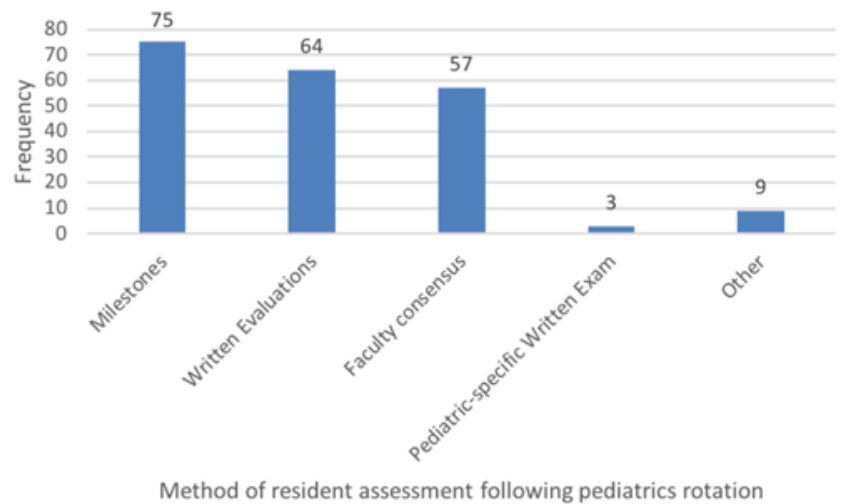

FIG. 4. Frequency of various forms of resident assessment after pediatrics rotation. Figure is available in color online only.

in children, neurosurgeons regardless of subspecialty would be better prepared to address these needs in our communities.

\section{Conclusions}

Our study was designed to investigate the landscape of pediatric neurosurgical training during residency in order to further shape future educational efforts. Not only does this help to better elucidate the process of training pediatric neurosurgeons, but also it will help guide future efforts to improve the educational curriculum for pediatric neurosurgery during residency.

\section{References}

1. Lohani S, Cohen AR. Franc D. Ingraham and the genesis of pediatric neurosurgery. J Neurosurg Pediatr. 2013;11(6):727733.

2. Aurshina A, Hingorani A, Iadagarova E, et al. A trainee perspective to issues needing redressal in current vascular surgery training programs: survey results from 2004 to 2015. Ann Vasc Surg. 2018;51:31-36.

3. Accreditation Council for Graduate Medical Education. Neurological surgery case log defined case categories and 
required minimum numbers. 2019. Accessed February 3, 2020. https://www.acgme.org/Specialties/Documents-andResources/pfcatid/10/Neurological\%20Surgery

4. Sacks HA, Stepan JG, Felix K, et al. Subspecialty rotation exposure across Accreditation Council for Graduate Medical Education-accredited orthopaedic surgery residency programs. J Am Acad Orthop Surg Glob Res Rev. 2019;3(5):e088.

5. Royal College of Physicians and Surgeons of Canada. Competence by Design. 2017. Accessed February 3, 2020. http://www.royalcollege.ca/rcsite/cbd/competence-by-designcbd-e

6. Nousiainen MT, Mironova P, Hynes M, et al. Eight-year outcomes of a competency-based residency training program in orthopedic surgery. Med Teach. 2018;40(10):1042-1054.

7. Dougherty PJ, Andreatta P. CORR Curriculum-Orthopaedic education: Competency-based medical education-How do we get there? Clin Orthop Relat Res. 2017;475(6):1557-1560.

8. White MD, Zollman J, McDowell MM, et al. Neurosurgical resident exposure to pediatric neurosurgery: an analysis of resident case logs. Pediatr Neurosurg. 2019;54(3):181-187.

9. Hinds RM, Phillips D, Egol KA, Capo JT. Variation in pediatric orthopedic case volume among residents: an assessment of Accreditation Council for Graduate Medical Education case logs. J Pediatr Orthop B. 2018;27(4):358-361.

10. Breaud J, Bensaid R, Lacreuse I, et al. Do the residents attend the consultation? A national survey. Presented at: 72nd Congress of the French Society of Pediatric Surgery; September 16-18, 2015; Lille, France.

11. Breaud J, Talon I, Fourcade L, et al. The National Pediatric Surgery Simulation Program in France: a tool to develop resident training in pediatric surgery. J Pediatr Surg. 2019;54(3):582-586.

12. Potts JR III. Effect of new fellowship programs on resident case volume in pediatric surgery. J Am Coll Surg. 2019;229(1):126-133.

13. American Board of Surgery. The American Board of Surgery Booklet of Information-Surgery 2018-2019.
Accessed February 3, 2020. http://www.absurgery.org/xfer/ BookletofInfo-Surgery.pdf

14. Durham SR, Shipman SA. A 15-year review of pediatric neurosurgical fellowships: implications for the pediatric neurosurgical workforce. J Neurosurg Pediatr. 2008;1(6):429-432.

15. Samuel N, Philteos J, Alotaibi NM, et al. Canadian neurosurgery educators' views on stereotactic radiosurgery in residency training. World Neurosurg. 2018;112:e208-e215.

\section{Disclosures}

Dr. Limbrick received support from Medtronic, Inc., and Microbot Medical, Inc., for a non-study-related clinical or research effort that he oversaw.

\section{Author Contributions}

Conception and design: Limoges, Durham. Acquisition of data: Limoges. Analysis and interpretation of data: Limoges. Drafting the article: Limoges, D'Agostino. Critically revising the article: all authors. Reviewed submitted version of manuscript: Limoges, D'Agostino, Durham. Approved the final version of the manuscript on behalf of all authors: Limoges. Statistical analysis: Limoges. Administrative/technical/material support: D'Agostino, Durham. Study supervision: Durham.

\section{Supplemental Information Current Affiliations}

Susan Durham: Children's Hospital of Los Angeles, CA.

\section{Correspondence}

Natalie Limoges: University of Vermont Medical Center, Burlington, VT. natalie.limoges@uvmhealth.org. 